Article

\title{
A Case Study of the Sustainable Mobility Problem-Solution Paradox: Motility and Access of Metrorail Commuters in the Western Cape
}

\author{
Zinette Bergman ${ }^{1,2, *(D)}$ and Manfred Max Bergman ${ }^{1}(\mathbb{D}$ \\ 1 Social Research and Methodology Group, University of Basel, Rheinsprung 24, 4051 Basel, Switzerland; \\ max.bergman@unibas.ch \\ 2 Department of Psychology, University of the Witwatersrand, Johannesburg 2000, South Africa \\ * Correspondence: Zinette.Bergman@unibas.ch
}

Received: 19 March 2019; Accepted: 15 May 2019; Published: 18 May 2019

check for updates

\begin{abstract}
Public transport in general and passenger trains in particular are often advertised as solutions to mobility challenges due to their relatively low carbon footprint, high commuter load, high public safety, and contribution to reduced road congestion. But, how do these advantages apply to contexts characterized by inequality, poverty, and exclusion, and where train infrastructure is underdeveloped and poorly maintained? In this study, we examine the imaginaries and their associated transport predispositions of Metrorail users in the Western Cape province of South Africa. Based on 31 interviews conducted with Metrorail users, we explored how they conceptualize access to and use of mobility. The conceptual framework for this is provided by the Motility concept as developed by Kaufmann, Bergman, and Joye. Findings show that the context and culture defining the daily lives of Metrorail users reflect a reality, which is far removed from the way we theorize sustainable mobility. The limitations of spatial and social inequality, which create the mobility boundaries of Motility for these commuters, reveal a significant gap between their lives and the policies aimed to foster our sustainable mobility future. Despite this, the commuters of our study are highly mobile, and we end this article with an attempt to align these conflicting domains of dysfunctional contexts, mobility practices, and sustainability ideals.
\end{abstract}

Keywords: sustainable mobility; trains; mobility access; Metrorail; motility; Western Cape; South Africa; content configuration analysis

We must all learn ... to think differently. We need to learn how to transform our policies and strategies to address the challenges of sustainability. To reach the poor and vulnerable, we need targeted policies, active outreach, and integrated information to inform decision-making. We need to recognize and understand the multiple dimensions of poverty and vulnerability, and how they interconnect. And we need to break down silos ... between the economic, social, and environmental aspects of development.

Ban Ki-Moon, former UN Secretary General, 19 July 2016 [1]

Look, I think that the service Metrorail provides is really terrible. I started using the trains in 2006. It was sad back then and now it is even sadder. It gets worse every year. (J, 1) (Each interview was assigned a unique identifier, denoted by a letter, followed by the page number of the transcript from which the quote was taken.)

\section{Introduction}

Our mobility reflects the best and worst of human development. The displacement of goods, information, technology, and people has alleviated extreme poverty for billions of people and increased 
the quality of life and wellbeing for many more. It has also enabled unprecedented access to education, work, health, family and friends, and consumer goods. However, it also harms our environment, health, and wellbeing. The costs of persistent and increasing road, water, and air traffic congestion, the continued dependence on fossil fuels and associated destruction, as well as the millions of victims of accidents and pollution result in the "Triple $\mathrm{C}$ " challenge: How to reduce $\mathrm{CO}_{2}$, congestion, and casualties [2]? More precisely, how should societies reduce mobility's social, environmental, and economic costs, while maintaining the potential for development [3]?

At its broadest and most abstract level, the literature on sustainable mobility borrows the Brundtland framework of consolidating economic growth, social development, and environmental protection with a particular focus on inter-generational responsibility or fairness [4] (see also References [3,5]). Accordingly, sustainable mobility is defined as "the ability to meet today's transportation needs without compromising the ability of future generations to meet their transportation needs" [6]. By decreasing the dependence on private vehicles [7], encouraging modal shifts to public transport [8], and reducing the ecological impact of individual mobility behavior $[9,10]$, the main goals are ostensibly to "reduce the need to travel (less trips) ... reduce trip lengths, and to encourage greater efficiency in the transport system" [11] (p. 75) (see also References [12,13]). Many cities and regions across the globe are adopting some of these ideals, such as Baltimore and Portland in the USA, Vancouver and Calgary in Canada, Canberra in Australia, Birmingham and Windsor in the UK, Beijing and Chengdu in China, parts of New Zealand, the Philippines, and the Gauteng and Western Cape provinces in South Africa. Many cities and regions have embraced implicitly or explicitly the green transportation hierarchy, which ranks modes of transportation according to their degree of sustainability (Figure 1).

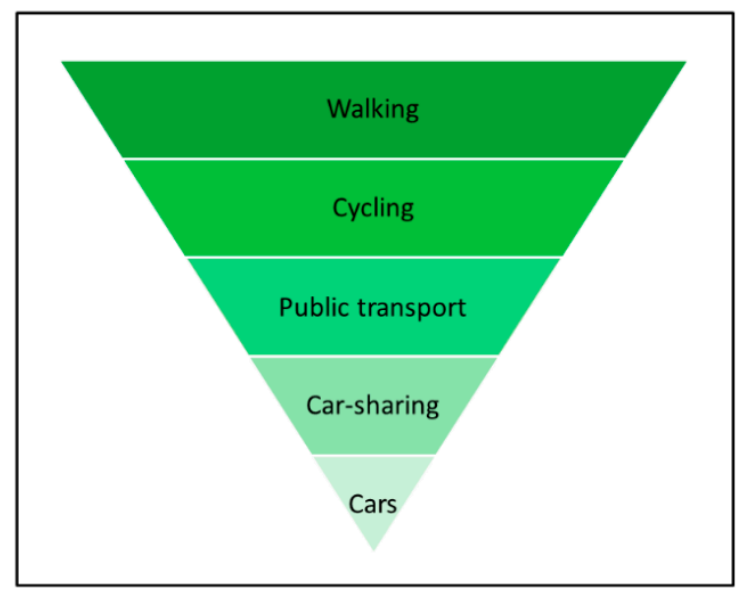

Figure 1. Green transportation hierarchy [14].

According to this individual transportation hierarchy, walking is the most sustainable form of mobility, followed by cycling, then public transport, such as buses, trams, and especially trains. High-occupancy vehicles or HOVs, which include car-pooling and car-sharing initiatives, are ranked next, and, finally, the least sustainable form of individual mobility encompasses single-occupancy vehicles (SOV) or private cars. This hierarchy is presented in numerous policy documents, urban planning forums, and government and city websites around the world, indicating not only the growing importance of sustainability more generally, but also an emergent normative agreement on how mobility and its sustainability consequences ought to be addressed: carbon-free cities in which daily activities are reorganized into decentralized clusters that favor human-propelled modes of locomotion.

Despite some forerunners, most cities and regions around the globe are far removed from these ideals. Nevertheless, many politicians, non-governmental and non-profit organizations (NGOs and NPOs), academics, city planners, and engineers aim to "unsprawl", "decongest", and "decelerate" cities by fostering public transport because large-scale public mobility systems, especially trains, are 
considered sustainable, given their reduced carbon footprint, high commuter load, increased safety, and contribution to reducing road congestion. However, large-scale public mobility systems also create new problems or exacerbate existing ones [15-18]. Kaufmann, Bergman, and Joye [19] (p. 735) described, for example, how access to large-scale mobility systems, such as the "train à grand vitesse" (TGV) in France or EasyJet in Europe, not only revolutionized people's perception of time and distance by creating new ways of living and working through "multi-residentiality", "multi-locality", and "multi-occupationality", but they also created new forms of social and spatial segregation, since only a limited number of people are able to leverage these advantages. In this way, mobility systems may inadvertently aggravate inequality and unsustainability, and the major challenge to sustainable mobility remains identifying viable strategies to balance the moral imperatives of "satisfying human needs, ensuring social equity and respecting environmental limits" [3] (p. 224). While the idea that large-scale public mobility systems contribute to new forms of spatial and social segregation is not new (e.g., References [20-24]), it seems to be largely absent from most debates on sustainable mobility. These predominantly Eurocentric and urban mobility solutions tend to have a strong impact on emerging economies, such as South Africa. Yet, how feasible, context-sensitive, and culture-aware are these approaches in developing economies, where $95 \%$ of future urban expansion will take place [25]? This is the central focus of our study as we aim to explore the suitability of normative, Eurocentric mobility models of sustainable mobility in a stratified South African context. We do this using a qualitative approach based on 31 in-depth, exploratory interviews with Metrorail commuters in the Western Cape, South Africa.

\section{Theoretical Background}

The concept of accessibility, conventionally used in the fields of transport planning, urban planning, and geography divides mobility access into land-use, transportation, temporal, and individual components [26], and it defines access in terms of individuals' potential to interact with mobility infrastructure [27]. While focusing on road networks, travel speeds, congestion levels, and individual or household activity programs makes accessibility easy to measure and interpret [26], this approach cannot account for the relationship between social determinants, such as inequality, exclusion, encultured mobility preferences, and mobility access.

To emphasize the socio-cultural dimensions of mobility access, Kaufmann, Bergman, and Joye [19] (p. 750) proposed that "spatio-social mobility may be realized differently or have different consequences across varying socio-cultural contexts". To systematize this notion, Kaufmann and his colleagues expanded on the concept of Motility, which denotes the actual and potential capacity of people, goods, technology, and information to be mobile. Motility is understood as a form of capital that enables people to access and utilize other economic, social, and cultural assets. It consists of interrelated components, relating to "access to different forms and degrees of mobility, competence to recognize and make use of access, and appropriation of a particular choice, including the option of non-action" [19] (p. 750). Given that our aim is to examine what access to sustainable mobility, such as trains, means to people in the stratified, developing context of South Africa, we focus primarily on access. According to Kaufmann, Bergman, and Joye [19] (p. 750), access refers to "the range of possible mobilities according to place, time, and other contextual constraints, and may be influenced by networks and dynamics within territories". This range is defined by access to mobility options and conditions. On the one hand, mobility options consist of the range of transportation means and communication available to commuters, as well as commuters' access to mobility services and equipment. Mobility conditions, on the other hand, refer to how accessible these options are in relation to the spatial distribution of infrastructure, the sedimentation of spatial policies, and the socio-economic position of individuals.

In this article, we use the access component of motility to examine train mobility in the Western Cape province of South Africa. Specifically, we analyze the perspectives of Metrorail users from two cities, namely Cape Town and Stellenbosch. As the largest commuter train service in South Africa, Metrorail transports approximately two million people per day [28]. In the Western Cape region, 
it consists of four lines-the Northern, Southern, Cape Flats, and Central Lines. The network is made up of 610 kilometers of track and 119 stations, which primarily serve to connect settlements, townships, suburbs, towns, and cities [28]. Using the access component as proposed by the theory, we examine how commuters navigate and conduct their daily mobility practices in relation to options and conditions, which define or constrain their mobility access. By examining these components, we aim to better understand what role mobility plays in their lives, as well as the implications this has on the greater mobility context of the Western Cape. The theoretical framework outlined by the motility concept lends itself to this study because South Africa, similar to many other developing economies, is characterized by high levels of inequality and exclusion, and because it faces a variety of structural problems relating to individual and public mobility systems $[15,16,29,30]$. A study on mobility access from the perspective of users in a developing context can highlight potentials and challenges for a global mobility future, especially because current and future mobility practices in emerging contexts will be a significant determinant of how not only sustainable mobility but especially sustainability itself will take shape globally. Accordingly, this article has three aims: (1) to systematize the options and conditions of mobility access as reported by the Metrorail users we interviewed; (2) to examine how these interactions shape commuters' potential to be mobile not only in relation to Metrorail, but also to the greater mobility context of the Western Cape region; and (3) to explore how the perspectives of these Metrorail users on mobility in general and trains in particular connect to notions of sustainable mobility.

\section{Materials and Methods}

This qualitative study is based on 31 interviews conducted with Metrorail users in the Western Cape, South Africa. Our sampling criteria included location (working or living in Cape Town or Stellenbosch), mobility mode (Metrorail), and frequency of use (weekly use in the past two years). Consequently, most interviewees lived or worked in the vicinity of Stellenbosch or Cape Town. These two locations, approximately $50 \mathrm{~km}$ apart, provided a large geographic catchment area of people from varied backgrounds and introduced a diverse range of mobility characteristics. Some interviewees, for example, came from affluent suburbs in Stellenbosch and Cape Town, such as Claremont or Tygerberg, while others came from middle- to low-income communities, such as Brackenfell, Belhar, and Eerste Rivier. Some traveled from as far as Paarl and Wellington (an additional 40 to $50 \mathrm{~km}$ inland, which corresponds to a two- to three-hour train commute, one-way), and many lived in surrounding informal settlements and townships, such as Khayelitsha, Bonteheuwel, Langa, Mitchells Plain, and Kayamandi. Although the majority of our interviewees were daily commuters, some commuted only occasionally. Among the men and women we interviewed were students, teachers, security guards, shop attendants, cleaners, drivers, administrators, couriers, repair men and women, managers, occupational therapists, personal assistants, and unskilled laborers. Our interviewees were Black, White, Asian, and Coloured (Coloured is an official term used in South Africa to denote individuals from a mixed ethnic background. Different ethnic typologies exist but the statistical office and most recent population census use the labels Black (80.5\%), Colored (8.8\%), White (8.3\%), and Asian or "Indian or other Asian" (2.5\%). It should not be confused with pejorative and racist usages in other countries, referring to non-whites), and, although the interviews were conducted in English or Afrikaans, the two most widely spoken national languages (among 11), some of our interviewees also spoke Xhosa, Sotho, North Sotho, and isiZulu. Although this is not a representative sample, our interviewees reflected South Africa's multi-cultural and diverse context. The interviews consisted of exploratory and semi-structured questions. Examples of exploratory questions included "Tell me everything that comes to your mind when you think about trains" or "What is your best memory with a train?" [28]. These questions aimed to elicit extended narrative responses regarding interviewees' mobility experiences. Semi-structured questions included "When, where, and how often do you take trains?" or "What do you think will happen with trains in the future?". These questions aimed to prompt specific mobility needs, preferences, and aspirations. 
We analyzed the interviews using content configuration analysis (CCA) [31,32]. CCA is a type of qualitative analysis related to qualitative content and thematic analyses. It can be used on all non-numeric data including written and visual sources [32]. It is applied in the fields of education, health, business studies, psychology, economics, philanthropy studies, sociology, and sustainability studies. The main strength of this method lies in its flexibility, since analytic strategies can be adapted to research foci or researcher needs [32]. In this study, for example, we used CCA to conduct a quasi-deductive analysis based on theory-guided top-down coding, using the access component of the motility framework as a structuring principle and coding framework [19]. As a first step, we identified all mobility-related elements in the data. Next, we coded and classified these using the dimensions of motility access. This analysis enabled us to (a) identify if the dimensions of motility as outlined in the theory were present in the interviewees' narratives, and (b) how these dimensions relate to the particular mobility experiences of commuters in the context of Metrorail in the Western Cape. Finally, we analyzed each dimension of motility access to systematize what they mean from the perspective of the Metrorail commuters. Systematizing the range of motility options and conditions that characterize the daily mobility experiences, and how they constrain actual and potential capacities of commuters to be mobile allowed us to link mobility preferences and behaviors with the mobility context and environment.

\section{Results}

We sorted the data according to these six dimensions across a macro-, meso-, and micro-level, as illustrated in Figure 2.

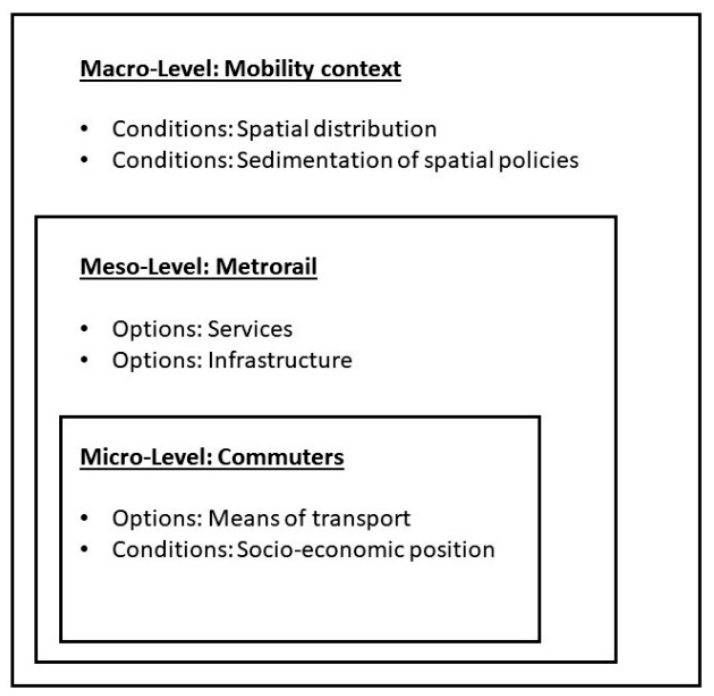

Figure 2. Motility access from the perspectives of Metrorail interviewees.

At the macro-level, motility access relates to the greater mobility environment, specifically the spatial distribution of mobility infrastructure and the sedimentation of spatial policies. At the meso-level, motility access concerns Metrorail services and infrastructure. The micro-level connects Metrorail commuters to their means of transport and socio-economic position.

\subsection{Macro-Level: The Greater Mobility Environment}

Spatial distribution of mobility infrastructure: Metrorail commuters described their greater mobility environment predominantly in terms of the limitations of public transport infrastructure. These limitations manifested on multiple levels. Regionally, public transport was reported as restricted or unavailable, modal choices as limited, and existing infrastructure as too far away. Two examples are provided below. 
When the trains are late, what are you supposed to do? You must just sit and wait because you don't have other alternatives. There isn't a taxi here that you could take, or there isn't a bus service in place. $(\mathrm{A}, 3)$

You see, because when it is off peak, even for us who need to walk home from the station. For women it is actually more dangerous. And you see, in the area where we live, where I live in Kleinvlei, the police station is right next to the train station, which means they are very visible so the people can walk and so on. But see now its winter and it is dark early. So already by 6 o'clock, its dark and then people still have to walk. So, no way. It is really very dangerous. For a woman to walk that time of the morning or evening is very dangerous. $(\mathrm{W}, 4)$

From the perspectives of the Metrorail commuters we interviewed, the spatial distribution of mobility infrastructure was defined in terms of its lacunae. Commuters reported that mobility networks were either underdeveloped, dilapidated, or non-existent. Examples included that the entire catchment area of the Stellenbosch region was serviced by a single-track rail line, which caused frequent and long delays, or the differential levels of service between Northern and Southern lines or between the so-called "business trains" and the "normal trains", the former receiving preferred treatment at the expense of the latter in terms of scheduling, solving delay issues, and overall service. Also mentioned was the absence of a feeder bus system, which resulted in long, inconvenient, or dangerous journeys to reach train stations. In some instances, commuters walked for more than one hour, sometimes starting well before 5:00 a.m., to reach the nearest station. Consequently, this lack of mobility infrastructure placed significant constraints on their mobility access.

Sedimentation of spatial policies: Public transport policies were described in similar terms since commuters reported that policies where either lacking or promised improvements were not implemented. Some examples are provided below.

They say that by next year they will launch a new system but I know that nothing is going to come of it. I don't think it's the trains that are the problem. I think it is the way it is being managed. [... ] Because a management that is focused on service delivery will not provide a poor service. They would maintain things well. They would ensure that the trains are running on time. Um, they don't really care about the people. $(\mathrm{J}, 2)$

That's why, that's why, their planning was really very, very bad for these lines. [ ... ] They really need to, they really need to improve their service. Funny enough, I actually saw the other day in the Argus [Cape Argus, a local newspaper] that they are planning to. But you know they always make plans and makes plans and make plans, and nothing ever comes from it. The Minister of Transport has, just the other day. There was an article in one of the newspapers: They are planning to do something but they never get so far to actually deliver anything. So, it's really, it's really a problem you know. It is a big problem and unfortunately this is the way it is. $(\mathrm{W}, 2 / 3)$

When interviewees spoke of mobility options, they lamented the inadequate mobility planning of their mobility environment. According to interviewees, politicians often promised infrastructure investment, better services, or more alternatives, which rarely materialized. Many commuters believed that regional spatial policies were either insufficiently formalized or non-existent. Consequently, many commuters felt trapped in a deficient mobility environment characterized by the absence of a vision for current or future public transport. The stasis of their mobility environment and the lack of policy intervention to remedy it left commuters feeling abandoned by policy-makers, who, according to our interviewees, were unconcerned for their welfare. In this context, many of the commuters we interviewed had access to only one public mobility source, Metrorail, while the only other mobility option was walking. 


\subsection{Meso-Level: Inside the Metrorail System}

Mobility options relating to the Metrorail system were located at the meso-level, particularly with services and infrastructure. Inadequacies of services manifested in several ways. According to our interviewees, commuter demand often outstripped carrying capacity, especially during peak hours, which resulted in severe overcrowding. Commuters also reported frequent delays and breakdowns, such as when "the train simply stops in the middle of nowhere" for long periods of time $(J, 6)$, which contributed to discomfort, given the lack of facilities and summer heat or winter cold. They also mentioned that replacements for canceled services were rarely provided, which further exacerbated overcrowding. Some examples from our transcripts are given below.

Yes, you see their name is not really Metrorail; their name is Metro-fail. No really, because you pay R133 [just over United States dollars (USD) \$9] for a [monthly] train ticket, which is fair-and-square, which is nice; the cheapest transport that exists. But their service is pathetic ... pathetic. Overcrowded trains, train delays, no announcements, you know. $(\mathrm{W}, 1)$

Metrorail ... Terrible service. Dirty trains. Um, affordable. Waiting. In the past thirteen days there was just one day when all the trains, and I use four trains every day, there was just one day when all the trains were on time, all of them. $(J, 1)$

It happened in the morning. I was writing [exams] that morning. So, the trains were delayed, and they had been delays from early in the morning. I had no other option 'cause it was internal exams. Internal exams, my teacher shows no mercy. If you're late, you're late, you not gonna write. And it was June so I needed the marks to apply to university. People started clapping [she claps her hands loudly], the train came and people started to get on. I tried to get on, I tried, I fought and I fought. Then I could, one foot was on but the other foot was not. My bag was outside, my face was inside. I was holding on by the doors there, you know, onto the frame. I was holding by the door frame, so when the train was about to approach Bellville, it makes a turn but like a huge turn. I almost fell. If it was not for the person that was next to me, but a bit to the inside, I would have fallen. Cause this guy saved my life, he just grabbed me by my shirt and tie and held onto me. And then I couldn't breathe because I have asthma. I had already given up, I was going to die. But he pulled me in and other people also noticed that I was fainting. There was, I don't know what happened, I don't know where the people went, there was space, like they made space. I was able to lie down and then they gave me a space to breathe, but I almost died. (Y, 8)

Frequently connected to the inadequate service was the dire state of Metrorail's infrastructure. According to interviewees, trains were old and dilapidated, and the associated infrastructure was not maintained. Windows and seats were dirty, broken, or missing, and carriage doors did not function properly. Also reported were dilapidated train stations and platforms, malfunctioning communications and signal systems, and stolen copper cables that would bring the train system to a standstill. Some examples are provided below.

The trains themselves, look, there are some of the trains that are so dirty you can't see out of the windows and they don't tell you at which station you are arriving. So, if you don't know the route and its dark then you just guess. Sometimes you can't even see what's going on outside unless you open the window and, in the winter, this can become very uncomfortable when it is cold. So, this is really a bad service. $(J, 5)$

Well, it can't get any worse or much more anyway because they are just falling apart. I once reported a carriage that was so dilapidated that I thought it was unsafe. It felt like a wheel was going to come loose. These days it happens regularly that a train just stops in the middle of nowhere and then they say the train is broken. It can't go any further. I don't know what they do with it then, but it is just the service that becomes even more disrupted. $(\mathrm{J}, 6)$ 
While services and infrastructure accounted for the majority of data located in this access cluster, we identified a third dimension that related to the way people acted as a constraint to other peoples' access and use of trains. Some examples are provided below.

There were some days, sometimes when people have stolen the power cables. So the people can't go to work for at least a day or will be late by two or three hours. So yes, I think this is actually a terrible experience, especially if there is work to be done. They steal the cables a lot, yes. (N, 2)

Interviewee: I remember it clearly. I was on the train with my mother, and this guy who came in like a normal guy, he then approached this pregnant woman and asked for her earrings, 'cause she was wearing diamond earrings, beautiful earrings. Then, he kindly asked for the earrings, so obviously the lady said "no". You know, like any other person. So, then he took out a gun, and then we all then realized, "oh, my gosh, this is a robbery". Then he told us to get down on the floor. So, we all got down and then this lady was just refusing. Guess what? She took the earrings and threw them outside, and said, "go, fetch them if you want them". Then the guy took her and threw her out [of the open door]. Yes, he threw her off. Like, that was the last time, that I used trains in my life. The last time. So, imagine with that trauma. $(\mathrm{R}, 3)$

Based on the experiences of the commuters we interviewed, we identified three types of human constraints: a threat to commuters, a threat to train infrastructure, or a threat to the functioning of the mobility system. Examples of the latter included commuters accidentally falling out of open doors, from the roof of trains, from riding illegally between carriages, or from accidents caused by pedestrians or vehicles failing to obey railway signals. Threats to train infrastructure occurred, for example, when angry and frustrated commuters vandalized trains, or when cables were stolen and sold for scrap metal. The most frequently mentioned human constraint to access, however, related to personal safety because of "skollies" (Afrikaans slang for thugs or gangsters). While most reported incidents related to theft or armed robbery, the vast majority of the Metrorail commuters we interviewed had been affected by gang-related violence, assault, murder, rape, vandalism, or drunk and disorderly behavior.

For all interviewees, unsatisfactory services, dilapidated infrastructure, and the possibility of becoming a victim or witness to a crime are part of Metrorail commuting. The experiences associated with services, infrastructure, and crime shape mobility system expectations, as system expectations shape mobility experiences. In this context, motility conditions such as the spatial distribution of mobility infrastructure and the sedimentation of spatial policies (or lack thereof) reveal how challenges constraining the mobility of the Metrorail users were not limited to Metrorail services but extended to the greater mobility environment in which Metrorail is embedded.

\subsection{Micro-Level: People and Their Environment}

The actual and potential capacity of commuters to be mobile at the micro-level of motility access connected to the commuters themselves and was mainly associated with the means of transport and their socio-economic position. The characteristics defining macro- and meso-levels intersected with commuters' mobility needs and aspirations. To examine how this manifested, we sorted interviewees' mobility preferences according to means of transport and the meanings they attach to them. Based on our analyses, we found that preferred mobility choices formed a distinct hierarchy, as depicted in Figure 3. 


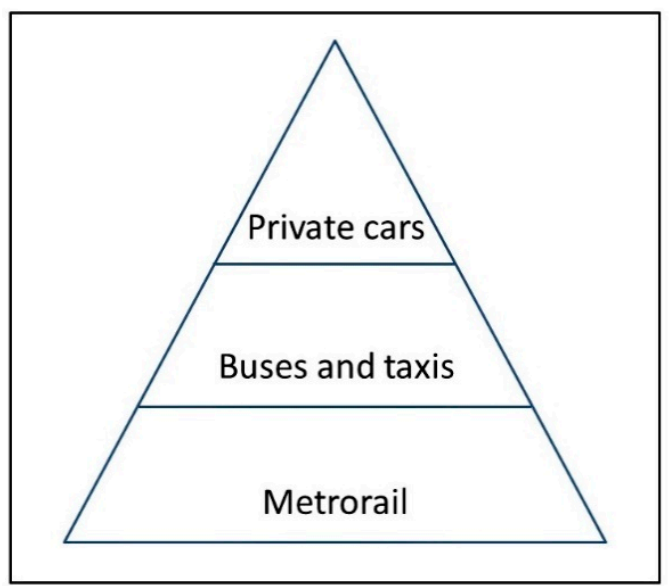

Figure 3. Preference of means of transport as ranked by Metrorail users.

Private cars occupy the top of this pyramid, whether or not the interviewees had access to a car. Cars were valued for their convenience, flexibility, comfort, reliability, and status. Instances in which Metrorail users resorted to car use, often shared, included important meetings, early-morning appointments, late-night events, weekly grocery shopping, special celebratory occasions, and transporting children. Indeed, most commuters reported that they would not take children on a train. Some examples are provided below.

Interviewer: Why don't you use trains more often?

Interviewee: Because using the car is more convenient. If I don't have to sit and wait for transport then I am not going to do it. When I can just get in and go, that is what I would do, that will always be my first choice. (E, 4)

If you miss a train, then you have to wait. So how do you deal with that when you need to get to work. With your car, you can make up some time, you can give the throttle a little bit. That's the only thing with trains, yes. [ ... ] Now these days, I don't use it anymore because I have to do a lot of things so I have to save time. But I also have to save money but I can't save money. Because with our trains you can't save time so you actually waste time so that's why I don't use the trains anymore because I have to use my car to move around. $(\mathrm{N}, 1 / 3)$

Other forms of public transport, such as buses and especially 8-30-seater minibus "taxis", occupy the second tier of the pyramid, as approximately 14 million South Africans use taxis daily. Reported as less convenient than private cars but still faster, safer, more efficient, and in closer proximity to where commuters lived, taxis have a fixed route but are flexible where they pick up and drop off passengers along their route. Taxis are also used to get to and from train stations. Thus, a work commute usually consists of walking before catching taxis or trains-nearly $10 \%$ of South Africans commute to work or school for three hours or more per day. Our interviewees tended to limit their train use to work commutes and used alternatives, especially taxis, on weekends. Overall, commuters reported that they prefer buses and taxis to trains. Some examples are provided below.

Interviewer: And do you think trains will be part of our future?

Interviewee: It better. We need it. We have too many cars on the road. Public transport is really terrible. I think the city of Cape Town is trying to do something about it with this new fast-tracked bus service. Um, unfortunately, it is not in the area where I live but what I have heard about it is that it is a very good service. $(J, 6)$

Interviewee: No way, forget it [he shakes his head]. No, I have now, like I said, only take it to work and back. [ ... ] When I am home, I would rather take a [minibus] taxi or a bus. 
Interviewer: Why would you rather take a taxi when you are at home?

Interviewee: Because it is quicker. The taxi is quicker and it picks you up near your home, and it drops you off near your home, and so on. So, if you have to go quickly, 10, 15 minutes, if you want to be somewhere quickly, then you take a taxi and of course if you want to go to the city it a naturally a completely different story. A completely different story. $(\mathrm{W}, 5)$

I prefer the bus. [ ... ] It's safer. You are almost guaranteed that you'll get a seat. And it doesn't really run late, and you get to school on time. And when it's raining, you don't worry about it delaying or being cancelled. $(\mathrm{Y}, 9)$

Metrorail, located at the bottom of the pyramid, was considered an affordable but least preferred mobility option. Affordability was reported as its most positive attribute, mentioned by nearly all interviewees. Some examples are provided below.

But we need the trains. There are thousands of people that use it every day and they don't have any other transport. $(\mathrm{J}, 6)$

Their price is really reasonable. It's much cheaper that what it would be with a car or a bus. As the price of petrol continues to rise more and more, people will become dependent on the train. $(\mathrm{A}, 3 / 4)$

[Metrorail] is inconvenient versus cost-effective. In the sense that it is always late, it is always overcrowded, and it is always wet or it is always too hot. $(G, 1)$

Metrorail's affordability, however, was also considered a trap toward dependence on the most underserved, inconvenient, and unreliable form of transport as stagnating wages, high unemployment rates, and rising petrol and food prices drained household budgets and made it less likely for the state to invest in, and commuters to afford alternatives.

By ranking mobility types according to preferences, we identified characteristics that related to how mobility modes are defined and separated. Privately owned cars were valued for their convenience, flexibility, comfort, reliability, and status. Buses or taxis offered no social status and much less flexibility and autonomy, but provided reliability and convenience due to geographic proximity, availability, and speed. Metrorail lacked these qualities and was, thus, unable to fulfil commuters' needs. Cost was an additional quality associated with this hierarchy. At the top of the pyramid, Metrorail users with access to a car frequently referred to trade-offs between cost and convenience, or cost and necessity. In the middle of the hierarchy, commuters reported how increasing fuel prices made alternative modes of public transport an attractive albeit inaccessible alternative, while most commuters at the bottom of this pyramid depended on Metrorail because it was the only or cheapest mobility option $(\mathrm{W}, 1)$. Thus, economics and status further defined this pyramid. While mobility preferences shaped the content of this hierarchy, it was the purchasing power and, by implication, status aspirations that ultimately maintained clear boundaries between the three mobility modes, evidenced by how our interviewees separated people into three categories: the poor, who walk or are stuck with Metrorail; "normal" people, who, depending on situation and context, may flexibly select from a variety of mobility modes; and the rich, who own and use cars.

Metrorail commuters who owned cars deliberately and selectively used train travel as an occasional and alternative mobility option, as the following two examples illustrate:

Um, I think it is really nice to take the train. I enjoy it. It's relaxing, it's a little bit more personal as opposed to when you sit in your car on your own. You know, it's actually nice to be part of the community to go in and out of the community; to do some people-watching. And it is a, I don't come from a background where people use a lot of public transport, and I find it interesting to see how other groups of people make their way through the day. I definitely prefer taking the train than driving. (M, 1-2) 
Um, people get into trouble at work because they are always late. Often, I can go back and fetch my car, and go with my car. But many, thousands of people, don't have a car that they could take. This is their only transport. I use it because it is cheaper and because I can read while on the train. I can't read while I am driving. $(\mathrm{J}, 2)$

Car owners who commute by Metrorail often took the more expensive "business express", reporting that they enjoyed the train commute because it was considered relaxing; they utilized travel time to read, sightsee, or prepare for the workday. They also mentioned that trains offer a cheaper mode of transport although they emphasized that they did not use trains to save money. Among this group, train cancellations were considered an annoyance that could be overcome by using their private vehicles. For important events or when they needed to travel during rush hour, they preferred using their cars.

Using the terminology of our interviewees, the "normal" people were located between the rich and the poor. However, the "poor" is a misnomer because people who must travel are not the poorest in South Africa. Metrorail commuters tend to be employed, are actively seeking employment, or they have resources to access education, apprenticeships, distant family and friendship network members, and so on. Even a dysfunctional mobility system is an improvement over not having a system at all. Living near a station is substantially better compared to communities without Metrorail and its feeder system. Metrorail offers a low transportation stratum in a hierarchy, but many people would be unable to go to school or work, see a doctor, or visit friends or family without it. Thus, when our interviewees refer to the poor, they mean those who have funds and a reason to take a train. Due to limited financial resources, the poorer commuters use Metrorail as their main form of transportation. The poor nevertheless reported access to alternatives, such as borrowed or shared cars, buses, taxis, or lift clubs. Their purchasing power was severely constrained and the costs associated with using alternatives required sacrifice and careful calculation. While the so-called rich and normal people were more flexible with regard to their mode of transportation, the former selected trains only for carefully selected and controlled trajectories; otherwise, they would use a car. The latter created a transportation patchwork based on specific contexts and motility needs, underpinned by a cost-benefit analyses of mobility options. Two examples are provided below.

Yea, yea, yes, I take it [the train] Monday to Friday, weekends I don't bother with the trains at all, like I've told you. We prefer to take the vehicle on the weekend of course. It is going to work out more expensive but you can do so much more with the vehicle because then you can do your shopping and things like that. $(\mathrm{W}, 6)$

And I have really realized that it is very good to take the train. Because you can save so much money, especially if you want to go out more and if you want to ... Like in the past, I couldn't even afford to go out for breakfast or lunch. You know, on weekends, if I want to relax, then I take my baby out or we go on an outing. And before I always had to think about the petrol money and, now, I can just do it. Because I know that I just have to buy a [train] ticket and then I know I don't have to worry throughout the month, if I have to go to this place or that place. $(G, 7)$

The poor were associated with the bottom of the mobility hierarchy. They lacked the purchasing power to afford alternatives and found themselves locked into an ailing and unreliable train system. Some examples are provided below.

You see, I am actually one of those fortunate ones because those other people have to also do their whole shopping with the trains right? They are not as fortunate as some of us ... Just put yourself, try to put yourself in those people's shoes, that person who lives in Bonteheuwel [a township near Cape Town]. He has to go to Cape Town and now he has his whole months' worth of groceries or whatever. I mean when you have a vehicle you just 
load it into the vehicle and there you go. But now you sit with seven or eight bags that you now have to hold onto and oh no. No, thank you. Forget it. (W, 6)

We pay, even though we pay less, but we pay. There are so many commuters. We buy so many monthlies [monthly tickets]. How much money does Metrorail make? Why can't they do that? Why can't they give us a comfortable, convenient place to sit in? $(G, 7)$

These narratives illustrate the significant relationship between economics and mobility choice. As commuters' purchasing power diminished, so too did their access to mobility modes and variability in mobility choices. A growing dependence on this cheap but unreliable mode of transport was associated with a decline in autonomy, security, status position, and life options. Finding themselves at the mercy of a dysfunctional mobility system, interviewees often expressed despair or resignation, as the following interviewees recounted:

Um, they don't really care about the people. Sometimes, when we are late, there are students on the trains who are supposed to be writing their exams. Once it happened that someone had the keys to open the bank and they are sitting with the keys, stuck at Muldersvlei station and can't take the train. Um, people get into trouble at work because they are always late. $(\mathrm{J}, 2)$

For example, yesterday morning. My train is at 5:45 a.m. No announcements, nothing. The train arrives at 6:30 a.m. Do you see? Now I have to let the people at work know that the train is late, but they don't understand. It's very frustrating. $(\mathrm{W}, 1)$

And there are some people who rely on the train to get to get them to work. And there are some employers who don't understand that sometimes the trains are just late and then they start to become difficult. And, so, it is possible for you to lose your job just because you use the train every day and because you need to trust it because it is your only transport that can get you to work. $(\mathrm{A}, 1)$

It was this sense of capitulation and precariousness at the bottom of the mobility pyramid that was particularly striking. Although the relationship between socio-economic status and mobility access is not new or surprising, we observed a relationship between economic position and access that was not limited to how poor people lacked access or choice due to diminished purchasing power. Rather, we identified a poverty trap at the bottom of this mobility pyramid that locked commuters into the Metrorail system. In a vicious cycle, people are trapped in an underpriced, affordable mode of transport that is unreliable and dangerous in ways that render their work and lives precarious, as outlined below:

- Metrorail cannot raise prices because its main customer base cannot afford a price hike and, worse, its infrastructure could be sabotaged because some customers would consider a price hike unjustified and unfair, given Metrorail's unsatisfactory service.

- Metrorail, thus, cannot modernize or expand services, which leads to further dilapidation, unreliability, and infrastructure decline.

- Given the high unemployment rate and availability of unskilled or semiskilled workforce in South Africa, employers have little patience with the poor who show up late or miss work due to a transportation breakdown. Long commutes, often in anticipation of delays or cancellations, in association with compromised diets and a poor health status among the most disadvantaged, further drain the energy and capacity of workers. Similar conditions and consequences are faced by commuting high-school or university students from the lowest income bracket.

- Especially commuters without alternative mobility options are, thus, caught in a trap because they are too poor to afford alternative and more reliable forms of transportation, causing the inability for Metrorail to improve its services and infrastructure. 
In sum, the dysfunctional public transportation system available to the poor keeps them locked in an unreliable transport system, which locks them into precarious education, work, and health situations, which keeps them locked in a precarious life situation, which keeps them locked in an affordable but unreliable and declining mobility system, which is unable to raise standards or increase service offers due to a lack of funding because their main customer base, the poor, are unable to afford higher prices.

\subsection{An Exception to the Rule}

As with most complex social phenomena, there are always exceptions to the rule. A good example here was the business train Metrorail provides in the Western Cape region. If we tried to fit this train into our mobility hierarchy, it would be placed at the top of the middle tier, above taxis and buses, but below private vehicles. This service provides a luxurious commuting alternative for business people at a premium price. This sub-division of Metrorail fits between cost and mobility mode and its association with comfort, convenience, reliability, and safety. Ironically, by removing affluent commuters from the first class section of a dysfunctional train system, and by developing a parallel train infrastructure, the business train side-steps the dysfunctionality of Metrorail's other trains at the cost of regular passengers. Worse, an affluent commuter class with a strong political clout and voice is, thus, eliminated from participating in reforming Metrorail. Affluent commuters are successfully pushing for an expansion of a privileged service, often subsidized by government funds, at the cost of mobility reforms that would benefit the majority of the population. The following examples illustrate the parallel train system:

You see there has always been this thing that has been bothering me. 'Cause I also took trains from Kuilsriver to Mitchell's Plein, so that line every time, every day, Monday to Friday at seven o'clock, there was a business class train that went past. In a month that train went delayed about two to three times maximum. That's the only time it would delay. But, and the ticket they pay like, it's huge, I think it's R1000 [approximately 70 USD] a month and everyone in that train gets a seat. It's seven o'clock, every day, everyone has a seat, everyone has a cup of coffee, and everyone has newspapers. I understand that they can afford it but why is it that at, seven o'clock, the business class train is always on time, every day, and then the other trains just go whenever and however. That's always been one of the things bothering me. Like is it because we pay R150 [approximately 10 USD] a month? Is it because, I never understood, that dilemma, because if they say, "good morning Metrorail users, trains are delaying due to cable theft, maybe in so and so, Metrorail apologizes for the inconvenience". Seven o'clock, the [business] train comes! Ahh, wasn't there cable theft? And I'm like "Whaaat?! What's happening? It's not right". [ . . ] Why should there be a business class train that comes at this time for such people, and then our train delays all the time. $(Y, 5-6)$

And these days they have these business class trains that provide a service to the business people, but why can't they also provide this business class to us normal people? Because see now, these people get there in the morning, then they get a cup of coffee. They come and sit there and then they get a newspaper. But you pay extra for that train. You pay R1000 a month or something, I'm not sure. (W, 7)

\section{Discussion and Conclusions}

In this article, we analyzed the access component of the motility framework, but also the greater mobility context within which access is embedded. This allowed us to link mobility preferences and behaviors with a mobility context and environment. That Metrorail is not fulfilling most commuters' expectations is well documented, and we embarked on this study with the understanding that the problems and challenges Metrorail commuters experience would be a central characteristic of our 
data. Our aim was not to catalog characteristics of a dysfunctional system, but to better understand how commuters connect to, and integrate dysfunctionality into their mobility needs and aspirations. The ability to be mobile is inseparably linked to needs and aspirations, whether they are personal, social, educational, economic, and beyond.

The motility framework we draw on proposes that people's actual and potential capacity to be mobile is best understood by examining the space where spatial and social mobility intersect. A defining feature of mobility is access, a necessary but insufficient condition for mobility. Our study revealed a context- and culture-sensitive mobility pyramid, whose tripartite nature is formed by access, economic position, and the resulting degree of flexibility. This pyramid is not a mere representation of interlocking mobility networks in the Western Cape region. It reveals how dimensions of safety, convenience, dependence, reliability, status, and autonomy converge in a hierarchical mobility structure.

Also striking in our study was the emphasis on economic resources, rather than ethnicity or race, with which commuters differentiate themselves and others. While ethnicity is mentioned occasionally, it was not used as a consistent marker of differentiation. Over the past two decades, the lines of demarcation between class and ethnicity somewhat diverged in South Africa, and it was more difficult to differentiate narratives about the rich, normal, and poor people versus White, Asian, Coloured, and Black South Africans. There were rare instances where rich signified white, and everyone else (non-whites) was labeled as either normal or poor. However, this euphemism was exceptional in our data.

In some of our previous work, we emphasized the dangers of dismantling Metrorail and replacing it with a modern mobility system, such as the Gautrain (a modern commuter rail system linking, among other things, central business districts, universities, shopping malls, upmarket residential areas, airports, and, still to be realized, some townships between Johannesburg and Pretoria). In many ways, the Metrorail's business express trains seem to mimic an exclusionary, parallel mode of train mobility - it is indeed comfortable, reliable, and safe, but it is also prohibitively expensive for the majority of South Africans, and, although the situation is improving, it still does not serve enough areas where the majority of South Africans live and work. Upmarket train systems risk creating and maintaining new forms of social and spatial segregation, shifting a segregated society based on race to a segregated society based on class, while concurrently reinforcing and possibly exacerbating poverty and exclusion for the majority.

In this sense, it is the dysfunctionality of Metrorail that will keep it going because it remains the most affordable form of public transport for the masses. It will remain affordable, even to poor people with jobs, and it is its cheapness of this mode of transportation that, in the absence of major structural reforms, imposes dysfunctionality on Metrorail. Thus, Metrorail is an enabler for poor people to reach distant jobs; however, given the strong relation between spatial and social mobility, it concurrently represents a hurdle to overcome in order to escape the bottom of the pyramid.

We began this article by introducing some of the main tenets of sustainable mobility as represented by the green transport hierarchy. This hierarchy, implicitly or explicitly, serves as the guiding framework for how sustainable mobility ideals are conceptualized in mobility studies and policy documents. Comparing the mobility hierarchy of our Metrorail users with the upside-down pyramid of the green transportation hierarchy, we observe how experiences and aspirations in the Western Cape are remarkably different from those propagated by the sustainable mobility paradigm. Comparing the mobility preferences of our interviewees with the green transportation hierarchy, we find that they are antithetical. At first glance, we may conclude that our commuters' mobility choices and aspirations are unsustainable because of their reliance on, or preference for fossil-fueled and individual-based mobility modes, especially cars. However, is this really the case? What would happen if we used sustainable mobility ideals as the benchmark to evaluate the mobility context in the Western Cape? What would the implications be for the Metrorail commuter context?

One of our interviewees lives in Khayelitsha, an informal settlement on the eastern fringe of the city of Cape Town, just over $30 \mathrm{~km}$ from the central business district. She shares a $6-\mathrm{m}^{2}$ shack with 
her infant and her aunt. Her aunt is 53 years old and unemployed. She cannot read or write, and she depends on whatever income her niece generates to survive. She neither owns a bicycle, nor does she use public transport, and she certainly has no access to a private vehicle. She rarely leaves the township, except for Sundays, when she walks to the nearby veld to attend an outdoor church service. During the week, she spends most of her time taking care of our interviewee's son and household. Every morning, she walks to the nearest water point to collect water for the day, which she carries back in a bucket balanced on her head. Some days she may do this several times. Occasionally, she walks to a nearby spaza shop, where she may buy phone credit or maize meal to make mieliepap for dinner. According to the green transportation hierarchy, and given that her mobility practices are limited to walking, she would be considered far more sustainable, compared to our interviewee, who uses taxis and trains to get to work a few times per week.

Although this is only an illustrative example, it exemplifies the challenges in applying Eurocentric concepts that are embedded in value systems and infrastructure availabilities that are difficult to translate into other contexts. That the aunt of our interviewee is attributed with a high level of sustainability in terms of her mobility practices is problematic, especially given that South Africa's official unemployment rate is at $27.2 \%$ [33] and youth unemployment at 54.3\% [34]. People living in circumstances such as these cannot be thought of as sustainable, even from the narrow perspective of the green transportation hierarchy. Thus, sustainable mobility must be adapted to reflect regional contexts and cultures in order to avoid being reduced to the wishful thinking of an educated, liberal, East Coast or European urban elite. While there is a lot of mileage in the sustainable mobility hierarchy, it needs to be adapted to reflect different contexts and cultures. In our case study, for example, sustainable mobility theory needs to take into account the lack and skewedness of mobility infrastructure in this developing and highly unequal society. Of course, if the first step toward sustainable mobility is to create an equal society and a well-funded and maintained mobility infrastructure, then the green transportation hierarch mobility model would work. However, if we want to pursue a greater degree of sustainability when considering people's mobility in the interim (and, by extension and based on the motility framework, make the mobility of goods, information, and technology more sustainable), then we have to revisit the green transportation hierarchy to take into consideration, first, regional contexts and cultures and, second, the extent to which some groups, regions, and countries need to develop economically in order to become more sustainable - across mobility modes and well beyond.

This case study provides insights into the challenges and opportunities defining a specific, encultured mobility landscape, thus providing important considerations for the theoretical assumptions upon which we base our sustainable mobility aims. This study could serve as an important impetus from which to develop context- and cultural-relevant, large-scale studies on mobility practices and mobility development. There are multiple, inter-locking contextual and cultural characteristics that shape people's actual and potential capacity to be mobile. The effectiveness of sustainable mobility interventions will depend on policies that can adequately account for these variations. In the Metrorail context, this would mean creating policies which simultaneously address contemporary and developmentally inspired socio-spatial dynamics. Given the poverty trap and resulting dependency cycle, an obvious recommendation would be to initiate structural reforms, including a baseline mobility access to ensure that commuters have access to a functioning, accessible, safe, and affordable public transport infrastructure. Improving the status quo, especially in relation to safety and reliability, could be funded by eliminating a parallel "business train" system. In addition, it is necessary to reformulate sustainable mobility theory and policies, which currently tend to privilege reducing environmental impact over the necessity of socio-economic development. The massive expansion of mobility of goods, information, technology, and people in the near future will take place mainly in the poorest and unequal societies. Sustainable mobility will only be attained through a global, national, and local commitment, through public and private partnerships, and through a careful balancing of socio-economic and environmental concerns. If sustainability privileges environmental protection 
over social and economic development, it risks being considered a luxury concern of educated, urban elites, especially in developing economies.

Author Contributions: Both authors contributed equally to the research.

Funding: This research received no external funding.

Acknowledgments: The authors would like thank the Mobile Lives Forum for making this research possible.

Conflicts of Interest: The authors declare no conflict of interest.

\section{References}

1. Ban, K.-M. Welcome Address. 38th Meeting, High-Level Segment-High-Level Political Forum on Sustainable Development 2016. Available online: http://webtv.un.org/\%C2\%BB/watch/part-1-38th-meetinghigh-level-segment-high-level-political-forum-on-sustainable-development-2016/5043498338001/?term= \&lan=french\&page $=5$ ?term (accessed on 17 December 2018).

2. Geerken, T.; Vercalsteren, A.; Borup, M. Review of the mobility domain. In System Innovation for Sustainability 2: Case Studies in Sustainable Consumption and Production-Mobility; Geerken, T., Borup, M., Eds.; Greenleaf Publishing Limited: Sheffield, UK, 2009; pp. 6-26. ISBN 978-1-906093-23-5.

3. Holden, E.; Linnerud, K.; Banister, D. The Imperatives of Sustainable Development. Sustain. Dev. 2017, 25, 213-226. [CrossRef]

4. Greene, D.L. Sustainable transportation. Int. Encycl. Soc. Behav. Sci. 2001, 15335-15339.

5. Holden, E.; Linnerud, K.; Banister, D. Sustainable passenger transport: Back to Brundtland. Transp. Res. Part A Policy Pract. 2013, 54, 67-77. [CrossRef]

6. Richardson, B.C. Sustainable transport: Analysis frameworks. J. Transp. Geogr. 2005, 13, 29-39. [CrossRef]

7. Charlton, C. Social Change and Sustainable Transport. J. Transp. Geogr. 2004, 12, 165-167. [CrossRef]

8. IPCC. The IPCC Fourth Assessment Report on Climate Change. Synthesis Report; Intergovernmental Panel on Climate Change (IPCC): Geneva, Switzerland, 2007.

9. Holden, E.; Høyer, K.G. The ecological footprints of fuels. Transp. Res. Part D Transp. Environ. 2005, 10, 395-403. [CrossRef]

10. Hunecke, M.; Haustein, S.; Grischkat, S.; Böhler, S. Psychological, sociodemographic, and infrastructural factors as determinants of ecological impact caused by mobility behavior. J. Environ. Psychol. 2007, 27, 277-292. [CrossRef]

11. Banister, D. The sustainable mobility paradigm. Transp. Policy 2008, 15, 73-80. [CrossRef]

12. Holden, E. Ecological footprints and sustainable urban form. J. Hous. Built Environ. 2004, 19, 91-109. [CrossRef]

13. Holden, E.; Gilpin, G. Biofuels and Sustainable Transport: A Conceptual Discussion. Sustainability 2013, 5, 3129-3149. [CrossRef]

14. Bradshaw, C. The Green Transportation Hierarchy; Ottawalk and the Transportation Working Committee of the Ottawa-Carleton Round-table on the Environment: Ottawa, ON, Canada, 1992.

15. Bergman, M.M.; Bergman, Z. The imaginary of the train of the future in South Africa: From public access to social exclusion. World Transp. Policy Pract. 2015, 21, 23-34.

16. Bergman, Z.; Bergman, M.M.; Pirie, G. Die Zukunft der Bahnmobilität in Südafrika: Vom Service Public zur sozialen Exklusion. Afr. Bull. 2015, 156, 6-7.

17. OECD. All on Board: Making Inclusive Growth Happen; Oecd Publishing: Paris, France, 2015; ISBN 978-92-64-21849-9.

18. Young, D.; Keil, R. Reconnecting the disconnected: The politics of infrastructure in the in-between city. Cities 2010, 27, 87-95. [CrossRef]

19. Kaufmann, V.; Bergman, M.M.; Joye, D. Motility: Mobility as capital. Int. J. Urban Reg. Res. 2004, 28, 745-756. [CrossRef]

20. Cass, N.; Shove, E.; Urry, J. Social Exclusion, Mobility and Access. Sociol. Rev. 2005, 53, 539-555. [CrossRef]

21. Dupont, V. Socio-spatial differentiation and residential segregation in Delhi: A question of scale? Geoforum 2004, 35, 157-175. [CrossRef]

22. Friedmann, J. The World City Hypothesis. Dev. Chang. 1986, 17, 69-83. [CrossRef] 
23. Grengs, J. Does Public Transit Counteract the Segregation of Carless Households? Measuring Spatial Patterns of Accessibility. Transp. Res. Rec. 2001, 1753, 3-10. [CrossRef]

24. Power, A. Social inequality, disadvantaged neighbourhoods and transport deprivation: An assessment of the historical influence of housing policies. J. Transp. Geogr. 2012, 21, 39-48. [CrossRef]

25. United Nations. Transforming our world: The 2030 Agenda for Sustainable Development; United Nations: Geneva, Switzerland, 2016.

26. Geurs, K.T.; van Wee, B. Accessibility evaluation of land-use and transport strategies: Review and research directions. J. Transp. Geogr. 2004, 127-140. [CrossRef]

27. Hansen, W.G. How Accessibility Shapes Land Use. J. Am. Inst. Plan. 1959, 25, 73-76. [CrossRef]

28. Bergman, Z.; Bergman, M.M.; Thatcher, A. Agency and Bandura's model of Triadic Reciprocal Causation: A case study of mobility among Metrorail commuters in the Western Cape, South Africa. Front. Psychol. 2019, 10, 411-425. [CrossRef] [PubMed]

29. Pirie, G. Sustainable urban mobility in 'Anglophone' sub-Saharan Africa. In Planning and Design for Sustainable Urban Mobility: Global Report on Human Settlements 2013; UN-HABITAT: Nairobi, Kenya, 2013; pp. 1-44. ISBN 978-92-1-132568-3.

30. Pirie, G.H. Virtuous mobility: Moralising vs measuring geographical mobility in Africa. Afrika Focus 2009, 22. [CrossRef]

31. Bergman, M.M. Content Configuration Analysis; StudyCube; University of St. Gall: St. Gall, Switzerland, 2011.

32. Bergman, M.M.; Bergman, Z. Perspectives of learners and teachers on school dysfunctions in South Africa. Educ. Chang. 2011, 15, 35-48. [CrossRef]

33. StatsSA. Quarterly Employment Statistics (QES), seCond Quarter 2018; StatsSA. Available online: http://www. statssa.gov.za/ (accessed on 20 January 2019).

34. Mcgregor, M. Labour Law Rules! 3rd ed.; Siber Ink: Cape Town, South Africa, 2017; ISBN 978-1-928309-14-7.

(C) 2019 by the authors. Licensee MDPI, Basel, Switzerland. This article is an open access article distributed under the terms and conditions of the Creative Commons Attribution (CC BY) license (http://creativecommons.org/licenses/by/4.0/). 